\title{
Travel health prevention
}

\section{Krzysztof Korzeniewski}

Department of Epidemiology and Tropical Medicine; Military Institute of Medicine, Warsaw, Poland

\begin{abstract}
All around the world there has been a rapid growth in the number of international travels. According to the World Tourism Organisation the number of international tourist arrivals reached 1,235 billion in 2016 and continues to grow at a high rate. This has been much due to the development of air transport (including low-cost airlines), increasingly common economic migration, a growing number of travellers visiting friends and relatives, and an increase in medical tourism. With tropical destinations becoming increasingly popular among travellers, doctors have seen a rising number of patients who seek medical advice on health risks prevalent in hot countries and health prevention measures to be taken in tropical destinations, especially where sanitation is poor. The risk for developing a medical condition while staying abroad depends on a variety of factors, including the traveller's general health condition, health prevention measures taken before or during travel (vaccinations, antimalarial chemoprophylaxis, health precautions during air, road and sea travel, proper acclimatisation, prevention of heat injuries, protection against local flora and fauna, personal hygiene, water, food and feeding hygiene), as well as the prevalence of health risk factors in a given location. Health prevention is a precondition for safe travel and maintaining good physical health; in the era of a rapid growth in international tourism it has become of key importance for all travellers.
\end{abstract}

(Int Marit Health 2017; 68, 4: 238-244)

Key words: health prevention, international journeys, travel medicine

\section{INTRODUCTION}

With tropical destinations becoming increasingly popular among travellers, doctors have seen a rising number of patients who seek medical advice on health risk factors prevalent in hot countries and health prevention measures to be taken in tropical destinations, especially those with poor sanitation. The risk for developing a medical condition while staying overseas depends on a variety of factors, including the traveller's general health condition, health prevention measures taken or neglected by a traveller (vaccinations, antimalarial chemoprophylaxis, health precautions during air, road and sea travel, proper acclimatisation, prevention of heat injuries, protection against local flora and fauna, personal hygiene, water, food and feeding hygiene), as well as the prevalence of health risk factors in a given destination. Travel health prevention is a precondition for maintaining good physical health and reliable information on travel health prevention can only be obtained during a pre-travel consultation with a medical professional. In order that a health care provider could recommend appropriate prevention measures, a patient must be ready to talk about the following subjects: the plan of a journey (country, part of the world, climate zone), the length of travel, departure and return dates, the type of accommodation (hotel, low-cost hostel), types of activities to be undertaken during travel (a beach holiday, scuba diving, mountain climbing, jungle or desert expeditions, cave exploration), previously received vaccinations (primary, complementary and booster doses), previously taken antimalarial medications, adverse events after the use of antimalarials or receiving vaccinations, chronic or ongoing conditions, types of medications taken regularly, carriage of infectious diseases (HIV, HBV, HCV), immunodeficiency disorders. All travel-related information is relevant and will help a physician to select and recommend appropriate prevention measures [1-4]. 


\section{IMMUNOPROPHYLAXIS}

Pre-travel vaccinations ought to be taken 4-6 weeks before the planned departure so there is enough time to receive all doses of the vaccine and confer full immunity [4]. Long-term travellers who are going to work or study abroad may be required by their employer or university authorities to receive specific vaccinations [5]. Travellers who received the primary vaccination course against infectious diseases in the past are recommended to take booster doses before travelling abroad. A vaccination against yellow fever is compulsory for travellers visiting the disease endemic countries in Africa and South America, while the vaccination against meningococcal disease is mandatory for all travellers to Saudi Arabia going on a pilgrimage to Mecca. In general, international travellers are recommended to receive pre-travel vaccinations against diphtheria, tetanus, poliomyelitis, viral hepatitis A and B, typhoid fever, cholera, rabies and Japanese encephalitis $[2,6]$.

\section{PREVENTION AGAINST INSECT BITES}

Before travelling to areas where vector-borne diseases are endemic travellers should receive medical advice on effective measures. To prevent insect bites travellers are recommended to use insect repellents containing 30-50\% DEET (N,N-diethyl-meta-toluamide) or $20 \%$ picaridin. While staying in tropical destinations they should be wearing clothes which cover as much of their body as possible (long-sleeved shirts or tops, long trousers), avoid staying outdoors from dusk to dawn, i.e. when insects are the most active, air-condition their living space, use bed nets and make sure insect screens are properly installed and tightly fitting all windows and ventilation grills [7-9].

\section{ANTIMALARIAL CHEMOPROPHYLAXIS}

The Centres for Disease Control and Prevention as well as the World Health Organisation recommend that travellers to malaria endemic areas should use one of the following drug regimens (the drugs need to be taken with food at the same time of the day): atovaquone/proguanil (1 tablet $250 \mathrm{mg} /$ /100 mg once daily, starting 1-2 days before departure, during travel and 7 days after return), doxycycline (tablet or capsule $100 \mathrm{mg}$ once daily, 1-2 days before departure, throughout the stay in endemic areas, and 4 weeks after travel), mefloquine (a tablet $250 \mathrm{mg}$ once weekly, 1-2 weeks before travel, during travel, and 4 weeks after return; the drug is not well-tolerated, possible side effects include neuropsychiatric disorders), chloroquine (a tablet $500 \mathrm{mg}$ once weekly; 1-2 weeks before travel, throughout the stay in endemic areas, and 4 weeks after travel; it needs to be remembered that the emergence of chloroquine-resistant Plasmodium has had a significant impact on the application of chloroquine to treat malaria) $[10,11]$.

\section{TRAVEL HEALTH KIT}

It is extremely important that international travellers are equipped with a medical kit containing the necessary medications and personal prevention products; they should also remember to take all essential documents with them. The travel health kit should contain prescription and contraceptive medications for the whole period of travel, antimalarials, insect repellents, antidiarrhoeals, analgesics/antipyretics, antihistamines, antibiotics, antibacterial ointments and creams, eye and ear drops, dressing materials, an extra pair of glasses or contact lenses (travellers with a sight defect), sunglasses and a sunscreen. On top of this, travellers to exotic destinations ought to obtain a health insurance (covering the costs of treatment, medical evacuation and repatriation and accident insurance), the International Certificate of Vaccinations and a photocopy of their passport. The contents of a travel health kit should be tailored to a traveller's individual needs and health requirements, the length of travel and the health risks prevalent in a given destination. Before taking any drug, travellers should always read the patient information leaflet containing the information on contraindications for use and possible drug interactions $[2,12,13]$.

\section{AIR, ROAD AND SEA TRAVEL}

\section{TIME ZONE CHANGE SYNDROME (TRANS-MERIDIAN FATIGUE, JET LAG)}

It is a medical condition resulting from long-distance trans-meridian flights taken within a short period of time. Travelling east tends to be more troublesome for travellers as it means their day-night cycle is shortened; travelling west, on the other hand is less problematic because travellers gain extra hours and it is generally easier for the human body to adjust to a longer day-night cycle. Jet lag is primarily caused by physiological disorders (sleep pattern, basic metabolism) and the alternation of the circadian rhythm, which affects the secretion of hormones (melatonin and cortisol). Its most common symptoms include sleep disorders (mainly insomnia), fatigue, loss of appetite, irritability, difficulty concentrating, headaches and gastrointestinal disorders. Once the body gets back to its normal circadian rhythm, symptoms of the jet lag disappear. The recovery period is usually one day per one time zone crossed. In order to reduce the symptoms associated with the time zone change syndrome travellers are recommended to get a good night's sleep before they fly, eat well and avoid alcohol and caffeinated drinks as they have a dehydrating effect [14-16].

\section{ECONOMY CLASS SYNDROME}

This is a medical condition which is associated with long-haul flights; it may develop if a traveller remains seated for long hours. If a person remains immobile for a long 
period, the compression of the thigh and the popliteal fossa decreases venous blood flow and can lead to venostasis. Prolonged venostasis can progress into deep vein inflammation in the lower leg and subsequently into deep vein thrombosis. The initial symptoms of the economy class syndrome include feet swelling, especially around the ankles, as well as popliteal and calf pain. Within 3 days following long-haul air travel other signs and symptoms such as localised pain, swelling, redness and warmth in the lower leg, as well as elevated body temperature can occur. There is generally a higher risk of the deep vein thrombosis in older travellers, patients with hypercoagulability or phlebitis, patients with varicose veins, travellers after major vascular surgeries, patients with or after a lower limb fracture requiring cast immobilisation, pregnant women (particularly in the third trimester), women taking oral contraceptives, cancer patients.

A blood clot or its fragment can break off from the vein and travel with the bloodstream through the right atrium and ventricle into the pulmonary artery and other vessels of the pulmonary circulation. If a blood clot blocks the pulmonary artery, pulmonary embolism occurs. Pulmonary embolism usually manifests with shortness of breath, rapid, shallow breathing, chest pain (especially when breathing in) and a fast heart rate. When the blood clot is large, it may get stuck in the atrium or the ventricle causing a sudden drop in the blood pressure, loss of consciousness and eventually death. The risk of the economy class syndrome can be reduced by observing certain precautions: frequent changes of the body position - from the sitting to the standing one (if possible), walking along the aisle of the plane, avoiding dehydration (regular fluid intake). These precautions are especially important for patients with hypercoagulability or phlebitis. High-risk passengers are recommended to wear compression bands or stockings during the flight [17-19].

\section{MOTION SICKNESS (KINETOSIS)}

Motion sickness is a common condition associated with car, sea, air or less frequently rail travel which is caused by intense motion. It occurs when there is a mismatch of information between the auditory and the visual systems. While the visual system registers movement and sends appropriate signal to the brain, the vestibular system, which is responsible for the sense of balance, does not register motion but reacts to kinetic changes (braking or accelerating). The differences between the information received by the two systems result in motion sickness with symptoms including nausea, vomiting, dizziness, sweating, excessive salivation or cardiac arrhythmia. Motion sickness most often affects girls aged 2-12. Generally, it is more often seen in passengers rather than among crew members (sea travel). Similarly, in case of overland travel, passengers are found to be more often affected than the driver. Motion sickness affects approximately $1 \%$ of all air travellers. To prevent motion sickness, a traveller should choose a seat where they will experience the least movement, e.g. the front seat in a car or on a bus (but not near the wheels of the bus); a forward-facing seat on a train; a seat in the middle of a boat or a ferry; a seat by the window, next to the wing and on the right side of the plane. Before journey, travellers should avoid heavy meals and fizzy drinks $[20,21]$. In Poland, the most popular over-the-counter medication to prevent motion sickness is dimenhydrinate (Aviomarin tab. $50 \mathrm{mg}$ ); it should be taken 30 minutes before travel at a single dose of 1-2 tablets (the onset of action after application is $20-30$ minutes and the duration is usually 4-6 hours). The drug is contraindicated in children under 2 years of age, patients with epilepsy, pregnant or breast-feeding women [4].

\section{TRAFFIC ACCIDENTS}

According to the World Health Organisation, road traffic injuries are a major cause of death and disability among international travellers, particularly among young travellers. Injuries due to road traffic accidents account for nearly $50 \%$ of deaths or disabilities in the age group 5-44. Travellers are at a 10-time greater risk of death from road traffic injuries than from infectious or invasive diseases. Most traffic accidents occur in low-income countries where a high proportion of fatal or serious injury collisions result from bad roads and non-compliance with traffic laws (if they exist at all). It is estimated that around 3,500 people (passengers, pedestrians, drivers), including 1,000 children, die in traffic-related accidents every day [22]. It is estimated that the number of deaths from road traffic injuries is likely to double by 2020 . The majority of deaths ( $85 \%$, including $96 \%$ children) are reported from developing countries; mostly from Muslim countries such as Egypt: 42 deaths per 100,000 inhabitants, Libya 40/100,000, Afghanistan 39/100,000, Iraq 38/100,000. In order to avoid road collisions and traffic-related injuries travellers, especially those to Asia and Africa, need to follow some basic travel-related precautions, i.e. they should always fasten their seatbelts, avoid crowded buses or minibuses, avoid travelling at night, and when they drive always adjust their speed to match the weather and road conditions [4, 23].

\section{TRAVEL HEALTH PRECAUTIONS}

Before travelling abroad, especially to destinations with harsh environmental conditions and poor sanitation, travellers need to acquire some basic knowledge on the acclimatisation, i.e. the process of adjusting the human body to new environmental conditions, personal hygiene, accommodation and clothing hygiene as well as food and feeding hygiene. When visiting tropical destinations, particularly the areas where infectious and parasitic diseases 
are endemic, a traveller must take all the necessary health precautions and follow the basic guidelines on disease prevention at any time. This will prevent the development and spread of diseases and other medical conditions [1-4].

\section{PREVENTION AGAINST INSECT BITES}

- Use insect repellents;

- Use mosquito nets;

- Wear proper clothing to cover your body (long trousers, shirts with long sleeves);

- Do not stay outdoors after sunset, especially close to standing water which is the breeding ground for insects;

- Stay in air-conditioned accommodation, put insect screens on all windows and ventilation grills.

\section{PREVENTION AGAINST ANIMAL BITES}

- Avoid contact with animals, both domesticated (dogs, cats) and wild animals - do not approach or feed animals!

- If you have been bitten or scratched by an animal, wash the wound with soap and water, immediately contact a health care provider (to receive post-exposure vaccination against rabies).

\section{WATER, FOOD AND FEEDING HYGIENE}

- Wash your hands with soap and water before every meal (if water and soap are unavailable, use disinfecting gel or tissues);

- Drink bottled or boiled water only;

- Avoid drinking water with ice cubes - they may be contaminated;

- Avoid buying food from street vendors;

- Avoid unpasteurized dairy products.

\section{PREVENTION OF TRAFFIC ACCIDENTS}

- Do not drink alcohol if you are planning to drive;

- Always wear your seatbelt;

- Use child car seats;

- Wear a helmet while riding a bicycle or a motorcycle;

- Avoid travelling on crowded buses or minibuses;

- Avoid travelling after sunset.

\section{OTHER HEALTH PRECAUTIONS}

- Prevention of altitude sickness in high mountain areas (acclimatisation) and sun protection (using sunscreens);

- Avoid tattooing, piercing your ears or navel, injections with non-sterile needles (the risk of HIV, HBV, HCV infection);

- Always use condoms if you engage in casual sex (the risk of sexually transmitted infections);

- Do not walk barefoot in areas where local animals defecate (the risk of cutaneous larva migrans);

- Have good personal hygiene: wash your feet, armpits and groin regularly, prevent skin irritation (the risk of mycosis);
- Have good oral hygiene (brush your teeth at least three times a day, use bottled or boiled water only for rinsing your mouth).

\section{ACCLIMATISATION}

Environmental conditions in countries with a hot climate and poor sanitation are clearly different from those which prevail in the temperate climate zones. Travellers arriving at a new tropical or subtropical destination need to get acclimatised. Acclimatisation is a complex process of adjusting the human body to novel environmental conditions such as the change in the time zone, the geographical location (climatic and sanitary conditions) or the altitude (atmospheric pressure). It normally takes from a few days to several months, depending on the differences between the conditions prevailing in the travellers' home country and the new environment. During the acclimatisation period the human body must first adapt to unfamiliar climatic conditions (temperature and humidity); this is achieved through the changes in the functioning of the cardiovascular, respiratory and urinary systems. Also, the digestive system needs to adjust to different type of cuisine and lower standards of sanitation. Some travellers will require a longer period of adjustment than others, notably the elderly or obese individuals. Because travellers loose large amounts of water and electrolytes from sweating and evaporation, they are more susceptible to fluid and electrolyte imbalance (the sweat of unacclimatised travellers contains 2-3 times more salt than the sweat of those fully acclimatised). This can lead to heat injuries including a heat stroke, heat exhaustion or muscle cramps. For this reason, travellers are strongly recommended to intake at least 3 to 4 litres of mineral water or isotonic drinks per day during the acclimatisation period. In addition, during the acclimatisation the body needs to adjust its biological clock to a new daily schedule and types of activities. When the weather is hot and humid, activities requiring considerable effort (sports or intense physical activity) should be scheduled for early morning hours or late afternoon rather than midday. It is also very important that travellers to tropical destinations maintain a regular sleep pattern with at least 7 hours of sleep per day and have enough rest during the heat of the day; this will help them maintain good health and physical fitness [4, 24-26].

\section{HEAT INJURIES}

The constant body temperature is the effect of maintaining the balance between the heat production and the heat loss. The human body is capable of absorbing the heat radiating from objects whose temperature is higher than that of a human body; it can also absorb direct or reflected solar radiation. At high ambient temperatures the human body needs to release the excess heat to maintain its normal 
temperature. This can be done through a variety of ways including radiation, transfer or conduction, evaporation of water through the skin and the lungs, exhaling heated air or excreting urine and faeces. The skin is the major organ controlling the heat production and the heat loss mechanism. Because it is sensitive to heat and cold, one of its roles is to inform the brain of the changing environmental conditions and the necessity to speed up or slow down the cooling mechanism. The thermoregulatory function of the skin affected by a disease is less effective than that of normal healthy skin. Thermoregulation is also negatively affected by a variety of internal and infectious diseases. Overweight and obese people are more likely to overheat, especially if the air is hot and humid. When the air is dry, the human body can easily release excess body heat by perspiration and the body temperature does not change much (in the dry tropical climate even the temperature exceeding $50^{\circ} \mathrm{C}$ is considered safe for humans). In the wet tropical climate, on the other hand, the temperature higher than $30^{\circ} \mathrm{C}$ gives a person the sensation of sultry heat and causes the body temperature to rise rapidly. Under such conditions, a traveller often feels short of breath and starts sweating heavily, the sweat, however, does not evaporate and thus the body is unable to cool down. In temperate climates the sweating mechanism does not play a major role in thermoregulation. In tropical climates, on the other hand, it is a prerequisite for staying healthy, both for the native populations and for travellers from temperate climate zones. The common risk factors of heat injuries include: insufficient intake of water and electrolytes, excessive physical effort, working outside when the air temperature is high, lack of sun protection of the exposed body parts (sun stroke), the use of drugs reducing perspiration (atropine, antihistamines), alcohol or caffeine abuse (a dehydrating effect), obesity, an infectious disease presenting with elevated body temperature, wearing clothes made of synthetic fabrics. A heat injury occurs as a result of heat imbalance, i.e. a change in the proportion of heat produced by the body through the metabolic processes and the heat gained from the environment to the evaporative heat loss $[4,26,27]$. The most commonly seen heat injuries include: heat stroke, heat exhaustion, muscle cramps and sun stroke.

Heat stroke. It occurs when the body's thermoregulatory mechanisms are disturbed by blocked perspiration - the main route of heat loss. The initial symptoms of the heat stroke include a headache, dizziness, nausea and vomiting, fatigue, high fever; they are next followed by neurological disorders and seizures. Heat stroke is a life-threatening condition, especially in patients whose body temperature is $>41^{\circ} \mathrm{C}$.

Heat exhaustion. It is a condition resulting from the loss of water and electrolytes (mainly sodium and chloride) leading to the peripheral circulatory failure, if untreated it may lead to a collapse. The main signs and symptoms are excessive sweating, headaches, elevated and poorly perceptible pulse, a drop in the blood pressure.

Muscle cramps. These are painful skeletal muscle cramps and spasms occurring as a result of excessive sweating (water and electrolytes loss). They most often affect the lower limbs.

Sun stroke. A heat stroke results from the direct exposure of the head/skull to sunlight, in particular the infrared radiation. It causes cerebral and meningeal hyperaemia which manifest with meningeal signs [26, 28].

\section{PERSONAL HYGIENE}

When visiting countries with a hot climate, or those lacking adequate sanitation, travellers are advised to maintain good personal hygiene. Travellers should take a shower at least once a day (and dry themselves well after the shower, especially the armpits, groins and the spaces between the toes). Swimmers should only bathe in designated areas, away from sea outfalls or habitats of local animals. They are also recommended to wear appropriate footwear, both while swimming in the sea (protection against urchins) and on the beach (protection against animal excrement and prevention of infections with helminth larvae). Travellers need to keep in mind that dental caries develops much faster in hot climate and therefore it is crucial to keep good oral hygiene. They should brush their teeth at least three times a day (after each big meal) using uncontaminated water (preferably bottled water). Skin care is also very important for travellers and skin care products should, on the one hand, protect the exposed skin from drying, but on the other, prevent excessive sweating around the private parts and in skin folds. It is extremely important to preserve the acid mantle of the skin and to maintain efficient work of the sebaceous and sweat glands which control sweat evaporation and thus are part of the thermoregulatory system. The skin should also be protected from direct sunlight and heat. If travellers choose to sunbathe, they should do it in a rational manner (sun tanning should take no longer than 20-30 minutes on the first day after arrival) and they should never sunbathe at midday because this is when the risk of sunburns is the highest. When they are staying outdoors they should always wear a sunscreen with an SPF matching their skin type (SPF 15-50) [4, 29].

\section{WATER, FOOD AND FEEDING HYGIENE}

The average daily water supply for consumption is 3-4 litres per person. Tap water needs to be filtered and disinfected by chlorination in order to provide physicochemical conditions for the decomposition of waste in wastewater and to kill pathogenic bacteria (unfortunately some pathogens 
are resistant to chlorination, these include Giardia intestinalis cysts or Cryptosporidium parvum oocysts). Travellers ought to make sure the ice cubes used to prepare their drinks are uncontaminated (preferably made from boiled water). Travellers must also know that the daily calorie intake is lower in hot climate areas compared to temperate zones (it obviously also depends on the traveller's age, weight, and metabolism). Excessive eating can be the cause of hyperthermia or indigestion. Naturally, the meals need to contain all the necessary nutrients. Foods should be stored properly (refrigerators, cold rooms). It is essential to make sure the diet contains sufficient amounts of carbohydrates (maize, rice). Before eating any fruits or vegetables a traveller should wash them with water and disinfect with diluted iodine solution (if possible), they must remember to peel raw fruits and vegetables and always do it themselves. Travellers need to avoid eating raw meat and seafood. They should also avoid eating too much at lunchtime as it is the hottest time of the day (it is recommended to have low-calorie and easily digestible meals instead). A traveller's diet should be well balanced and varied including a lot of fruit and vegetables. Travellers to tropical destinations should avoid drinking large amounts of alcohol and coffee because they have a dehydrating effect. They are recommended to drink still beverages (bottled) or fruit juice - either self-prepared or made by a street vendor in the presence of the buyer. Travellers are advised to choose pre-packed dairy products. They need to avoid the food which is too cold, as it may cause an upper respiratory tract infection, but also the food which is too hot because it can irritate or damage the gastric mucosa. Travellers should regularly wash their hands with water and soap, especially before meals. The meals should be eaten on the same day as they are prepared. It is very important to prevent contamination of food products with human or animal excreta. When travelling to countries with poor sanitation travellers should always choose dining premises which comply with the basic sanitary and hygienic requirements $[4,30,31]$.

\section{REFERENCES}

1. Hatz C, Chen LH. Pre-Travel Consultation. In: Keystone JS, Freedman DO, Kozarsky PE, Connor BA, Nothdurft HD. ed. Travel Medicine. 3rd Edition. Elsevier Saunders 2013: 31-35.

2. Freedman DO, Chen LH, Kozarsky PE, et al. Medical Considerations before International Travel. N Engl J Med. 2016; 375(3): 247-260, doi:10.1056/NEJMra1508815, indexed in Pubmed: 27468061.

3. Chen LH, Hochberg NS, Magill AJ. The Pretravel Consultation. In: Brunette GW. ed. Health Information for International Travel. Oxford University Press, New York 2017: 16-32.

4. Korzeniewski K. Medycyna podróży. Kompendium. PZWL, Warszawa 2016: 11-58.

5. Hartjes LB, Baumann LC, Henriques JB. Travel health risk perceptions and prevention behaviors of US study abroad students. J Travel Med. 2009; 16(5): 338-343, doi: 10.1111/j.17088305.2009.00322.x, indexed in Pubmed: 19796105.
6. National Center for Immunization and Respiratory Diseases. General recommendations on immunization - recommendations of the Advisory Committee on Immunization Practices (ACIP). MMWR Recomm Rep. 2011; 60(2): 1-64, doi: 10.1037/e546992006-001, indexed in Pubmed: 21293327.

7. Lupi E, Hatz C, Schlagenhauf P. The efficacy of repellents against Aedes, Anopheles, Culex and Ixodes spp. - a literature review. Travel Med Infect Dis. 2013; 11(6): 374-411, doi: 10.1016/j. tmaid.2013.10.005, indexed in Pubmed: 24201040.

8. Frances SP, Waterson DGE, Beebe NW, et al. Field evaluation of repellent formulations containing deet and picaridin against mosquitoes in Northern Territory, Australia. J Med Entomol. 2004; 41(3): 414-417, doi: 10.1603/0022-2585-41.3.414, indexed in Pubmed: 15185943.

9. Fradin MS. Protection from blood-feeding arthropods. In: Auerbach PS. ed. Wilderness Medicine. 5th Edition. Mosby Press 2007: 892-904.

10. Arguin PM, Tan KR. Malaria. In: Brunette GW. ed. Health Information for International Travel. Oxford University Press, New York 2017: 233-255.

11. Goodyer L, Rice L, Martin A. Choice of and adherence to prophylactic antimalarials. J Travel Med. 2011; 18(4): 245-249, doi: 10.1111/j.1708-8305.2011.00534.x, indexed in Pubmed: 21722235.

12. Goodyer L, Gibbs J. Medical supplies for travelers to developing countries. J Travel Med. 2004; 11(4): 208-211, indexed in Pubmed: 15541222.

13. Jong EC. Approach to Travel Medicine and Contents of a Personal Travel Medicine Kit. In: Sanford CA, Pottinger PS, Jong EC. ed. The Travel and Tropical Medicine Manual. 5th Edition. Elsevier, Marickville 2017: 1-16.

14. Sack RL. Clinical practice. Jet lag. N Engl J Med. 2010; 362(5): 440-447, doi: 10.1056/nejmcp0909838, indexed in Pubmed: 18041480.

15. Sack RL. The pathophysiology of jet lag. Travel Med Infect Dis. 2009; 7(2): 102-110, doi: 10.1016/j.tmaid.2009.01.006, indexed in Pubmed: 19237143.

16. Waterhouse J, Reilly T, Atkinson G. Jet-lag. Lancet. 1997; 350(9091): 1611-1616, doi: 10.1016/s0140-6736(97)07569-7, indexed in Pubmed: 9393352.

17. Reyes NL, Beckman MG, Abe K. Deep Vein Thrombosis \& Pulmonary Embolism. In: Brunette GW. ed. CDC Yellow Book 2018. Health Information for International Travel. Oxford University Press, New York 2017: 120-123.

18. Bartholomew JR, Schaffer JL, McCormick GF, et al. Air travel and venous thromboembolism: minimizing the risk. Cleve Clin J Med. 2011; 78(2): 111-120, doi: 10.3949/ccjm.78a.10138, indexed in Pubmed: 21285343.

19. Jong EC. Jet Health. In: Sanford CA, Pottinger PS, Jong EC. ed. The Travel and Tropical Medicine Manual. 5th Edition. Elsevier, Marickville 2017: 36-46.

20. Mills KL, Griffin MJ. Effect of seating, vision and direction of horizontal oscillation on motion sickness. Aviat Space Environ Med. 2000; 71(10): 996-1002, indexed in Pubmed: 11051306.

21. Eyeson-Annan M, Peterken C, Brown B, et al. Visual and vestibular components of motion sickness. Aviat Space Environ Med. 1996; 67(10): 955-962, indexed in Pubmed: 9025818.

22. World Health Organization. Global status report on road safety. Geneva, 2009. www.who.int/violence__injury_prevention/road_safety_status/2009 (30 0ct 2017).

23. Sherry MK, Mossallam M, Mulligan M, et al. Rates of intentionally caused and road crash deaths of US citizens abroad. Inj Prev. 2015; 
21(e1): e10-e14, doi: 10.1136/injuryprev-2013-040923, indexed in Pubmed: 24302480.

24. Wenger CB. Human heat acclimatization. In: Pandolf KB, Sawka MN, Gonzalez RR. ed. Human Performance Physiology and Environmental Medicine at Terrestrial Extremes. Cooper, Carmel 1988: 153-198.

25. Epstein Y, Moran DS. Thermal comfort and the heat stress indices. Ind Health. 2006; 44(3): 388-398, doi: 10.2486/indhealth.44.388, indexed in Pubmed: 16922182.

26. Bezruchka SA. Disequilibrium: Jet Lag, Motion Sickness, Cold Exposure, and Heat IIIness. In: Sanford CA CA, Pottinger PS PS, Jong EC. ed. Cold Exposure, and Heat Illness. Elsevier, Marickville 2017: 121-137.

27. Lipman GS, Eifling KP, Ellis MA, et al. Wilderness Medical Society. Wilderness Medical Society practice guidelines for the prevention and treatment of heat-related illness: 2014 update. Wilderness Environ Med. 2014; 25(4 Suppl): S55-S65, doi: 10.1016/j. wem.2014.07.017, indexed in Pubmed:25498263.
28. Epstein Y, Moran DS. Extremes of Temperature and Hydration. In: Keystone JS, Freedman DO, Kozarsky PE, Connor BA, Nothdurft HD. ed. Travel Medicine. 3rd Edition. Elsevier Saunders 2013: 381-390.

29. Fewtrell L, Colford JM. Water, sanitation and hygiene in developing countries: interventions and diarrhoea-a review. Water Sci Technol. 2005; 52(8): 133-142, indexed in Pubmed: 16312960.

30. Prüss A, Kay D, Fewtrell L, et al. Estimating the burden of disease from water, sanitation, and hygiene at a global level. Environ Health Perspect. 2002; 110(5): 537-542, doi: 10.1289/ehp.02110537, indexed in Pubmed: 12003760.

31. DuPont HL, Ericsson CD, Farthing MJG, et al. Expert review of the evidence base for prevention of travelers' diarrhea. J Travel Med. 2009; 16(3): 149-160, doi: 10.1111/j.1708-8305.2008.00299.x, indexed in Pubmed: 19538575. 